\title{
Socio-cultural factors in maternal morbidity and mortality: a study of a semi-urban community in southern Nigeria
}

\author{
Chike Okolocha, Jasper Chiwuzie, Suleiman Braimoh, Jacob Unuigbe, Patience Olumeko
}

\begin{abstract}
Study objective-To understand community based or socio-cultural factors that determine maternal morbidity and mortality in a semi-urban setting.

Design-The study is an exploratory multidisciplinary operations research and the instruments were focus groups and interviews.

Setting-Ekpoma, a semi-urban community with a population of 70000 in central part of Edo state in southern Nigeria.

Participants-Thirteen groups of women, two groups of men, and two groups of traditional birth attendants.

Results-There is a fairly good knowledge of haemorrhage but this is circumscibed by attitudes, practices, and situations that keep women away from or delay the decision to seek modern obstetric care.

Conclusions-For a fuller understanding of maternal morbidity and mortality, it is important to consider factors outside the hospital and formal medical practice. Furthermore, a change of existing knowledge, attitudes, practices, and situations can be enhanced through modelling on them.

(F Epidemiol Community Health 1998;52:293-297)
\end{abstract}

The level of maternal mortality in Africa, estimated at 100-fold to 200-fold that of the industrialised countries, is unacceptably high. ${ }^{1}$ Because of its very high fertility and death rates, Nigeria is said to account for 10 per cent of the world's maternal mortality. ${ }^{2}$ Moreover, most of these women suffer permanent disabilities.

The most common medical causes of maternal deaths are haemorrhage, toxaemia, infection, obstructed labour, and unsafe abortion. Deaths from most of these complications can be prevented if promptly and effectively managed. But in sub-Saharan Africa, the problem stems not only from inadequate health services, but is also the result of the interplay of many antecedent factors that could be social, cultural, economic and logistic, coupled with very high fertility. Such sex specific health problems ramify into the well known sociocultural difficulties and discriminations endured by women in Third World countries. ${ }^{3}$ Most of these women would have been neglected as children, overworked and underfed, espoused as adolescents, are quite often poor and illiterate, usually subjected to harmful traditional practices, denied equal social status in the society, and denied adequate family planning and maternal health services.

Although the limitations of health care delivery facilities and, therefore, personnel in Third World countries are quite well known, nonmedical factors, which are no less important have turned out to be intractable problems and are often conveniently ignored by confounded officials. Even in situations where modern health care facilities and personnel are available, many routine traditional or normative practices may prevent or delay the decision to seek proper and more effective care.

The objective of this study is to highlight these community based factors and their implications in maternal mortality and morbidity.

\section{Methods}

EKPOMA

Ekpoma was chosen as the study site because the social and political situation were conducive to working with the community. It is also an area being studied for a research project that aims to reduce maternal mortality resulting more specifically from haemorrhage, the established leading cause of maternal mortality in the locality. The University of Benin Teaching Hospital, the base of our research team, has had a long association with Ekpoma, which houses the institution's community health training centre. Also, the favourable attitude of the traditional political leadership enhanced our reception in the community.

Quite importantly, the community has had little experience with the many failed health projects in Nigeria. A semi-urban community with a population of 70000 , Ekpoma is about 84 kilometres north of Benin City, the Edo state capital.

STUDY DESIGN

Focus Group discussions (FGs) were held with a total of 17 groups of people drawn from the 13 areas that form Ekpoma. Thirteen of these (one from each area) were made up of women and two of men. Two other groups were made up of traditional birth attendants. Participants were recruited with the help of village heads. Each group was homogeneous with respect to sex, age (15-25, 26-35, and more than 35 years), educational status (no formal education versus primary school education or more), and occupational status (whether or not the individual worked outside the home for a regular income). Participants in each group were familiar with each other and the local environment. 
Table 1 Villagers' conception of haemorrhage

\begin{tabular}{ll}
\hline Identified causes & \% Of total respondents \\
\hline Retention of placenta and other products of conception & 80 \\
Big babies that cause tears & 100 \\
Abortions & 90 \\
Improper obstetric care & 75 \\
Hard work during pregnancy & 68 \\
Excessive consumption of alcohol & 63 \\
Too many previous pregnancies & 47 \\
"Sweet" foods (for example, milk) during pregnancy & 58 \\
Evil forces or enemies & 96 \\
Taboos (for example, adultery, incest, abuse or disobedience of husband, sex before & 98 \\
circumcision, sex in the afternoon or in the bush/farm) & 100 \\
Will of God & $\mathrm{n}=385$ \\
\end{tabular}

The number of participants in the sessions ranged from seven to 13 and each session lasted for between 45 minutes and one hour and 10 minutes. A female sociologist (trained for the purpose) acted as facilitator for women's groups while a retired primary school headmaster (also trained for the purpose) acted as facilitator for men's groups. All discussions were conducted in the local Esan language and recorded on audio tapes. The choice of facilitators and their training entailed both exposure to the technique of FG and an appreciation of our research objectives. And the entire purpose was to eliminate or reduce researcher bias. Analysis of recorded data started with an attempt to transcribe and translate all tapes used. The first tape took three weeks to be completely transcribed and translated into English. To avoid this unforseen delay we adopted an alternate strategy. A sociologist who understood Esan language and the goals of the FGs produced a report on the recorded discussion of each session. The tape and the report were then handed over to another member of our team (who also understood Esan) to verify that the report was an actual representation of the FG. Further checks and discussions by members of our team confirmed that our method of recording the FG data did not result in any loss or distortion of information.

FGs are guided group discussions intended to yield rich information on a given subject from a selected population. Recently, they have gained increasing acceptance as a reliable research methodology in the area of health and family planning. ${ }^{4}$ Ordinarily, FG participants should be unfamiliar with each other. But practical expedience dictated that participants in each of our FG sessions are familiar with each other. The sites for the discussions were also familiar to participants. These modifications of classic guidelines were necessary because the cultural context is such that people in this area were willing to discuss their views and experiences only with familiar members of the society. A similar scenario has been reported elsewhere. ${ }^{5}$

The principal themes for the discussions included: the local ideas of the signs of haemorrhage, possible times a woman may experience bleeding, perceived causes of haemorrhage, dangers and possible sequelae of haemorrhage, ways of preventing haemorrhage, available forms of treatment for haemorrhage, patterns of use and accessibility of various types of treatment for haemorrhage.
Our efforts at methodological rigour were important because despite the new acceptability of FGs, results from them are not always able to be transferred to larger populations. We therefore supplemented FGs with interviews conducted with schedules designed to explore the above themes. Interview respondents were selected to represent each of the FGs. For obvious reasons, the interview schedule was unstandardised. The interviews were conducted in the local Esan language but recorded in English simultaneously by two trained interviewers whose notes were later compared. Qualitative and quantitative data from the interview and FGs are presented.

\section{Results}

Views were generally consistent across categories of sex, age, educational status, and occupation. A summary of the views is presented.

\section{HAEMORRHAGE}

The people seem to have a clear perception of haemorrhage, which they called "blood flowing down a pregnant woman's legs", or "a pregnant woman having to change pads very frequently". There is also the general understanding that bleeding could occur any time during pregnancy, delivery, and in the "few" weeks after delivery. Table 1 lists the various reasons that were considered to cause bleeding.

\section{TYPES OF CARE}

It is generally believed that modern obstetric care methods cannot handle complications arising from the consumption of sweet foods, evil forces, indulgence or providence. This is one reason pregnant women with complications stay indefinitely with the traditional healers even in the face of obvious signs of danger. Causes are identified after appropriate diagnoses and examination. The frequency of occurrence was not predictable. With regard to cases not amenable to treatment in the modern sector, a respondent noted that "any woman who has not committed an abomination cannot suffer from bleeding. Pregnant women who bleed for a long time are those who have committed offences. It is very difficult to stop such bleeding until confessions are made. After that some cleansing ritual (which may include sacrifices and fines) is undergone before bleeding can be stopped. Without confession, the woman will bleed to death."

They strongly believe that both traditional and modern obstetric care practices are 
Table 2 Categories of haemorrhage and sources of remedy

\begin{tabular}{ll}
\hline Cases amenable to treatment in the modern health sector & $\begin{array}{l}\text { Cases not amenable to treatment in the modern health } \\
\text { sector }\end{array}$ \\
\hline Cases caused by: & $\begin{array}{l}\text { Cases caused by: } \\
\text { Consumption of sweet foods during pregnancy }\end{array}$ \\
Retention of placenta and other foreign bodies & $\begin{array}{l}\text { Machination of evil spirits and enemies } \\
\text { Adg babies that cause tear during pregnancy }\end{array}$ \\
$\begin{array}{l}\text { Too much hard work during pregnancy } \\
\text { Illicit or spontaneous abortion }\end{array}$ & $\begin{array}{l}\text { Illicit sex (for example, before circumcision, in } \\
\text { the afternoon or in the farm) }\end{array}$ \\
Lack of proper obstetric care & $\begin{array}{l}\text { Disobedience of husband } \\
\text { Will of God }\end{array}$ \\
Consumption of alcohol & \\
Too many previous deliveries & \\
\hline
\end{tabular}

effective and therefore should be used. They confirmed that even when they went to hospital for delivery, traditional medicines for treating complications like bleeding are taken along with them. The efficacy of the type of care a woman receives, however, is believed to depend on divine intervention. In the words of one traditional birth attendant, "human beings can only treat, it is God that heals". (Table 2).

PRIMACY OF TRADITIONAL CARE

The traditional sector is usually the first or only port of call for the pregnant woman, especially when there are no complications. Hospitals may be considered when complications occur. Only 18 per cent of all the women FGs reported in the hospitals before seven or eight months of pregnancy. Even a complication as serious as haemorrhage may not force these women to the hospital, except, of course, as a final resort. Seventy seven per cent reported they would remain with traditional health attention even after the third day of haemorrhage.

They seem to favour the traditional option for the following reasons; the traditional sector is easily available and accessible to the people. ${ }^{6}$ The traditional healers are there all the time and are called in when their services are needed in contrast with having to travel to the hospital; the requirements in the modern sector like registration and the need to pay a deposit before the women could be seen are some factors that keep the women away from them.

Considering that peasant incomes are below the national average, the aggregate expenses for registration, other medical fees and expenses as well as transportion costs especially in emergencies taking place out of usual hours cannot be afforded by the people. We have discussed the details of the economic and spatial problems in rendering modern obstetric care in a forthcoming publication.

Particular note should be taken of the local assumption on the superiority of traditional medical practice over the modern. According to one herbalist, "modern doctors are good but there are some ailments and conditions that the white man's medicine cannot handle. They even refer some of cases to us".

This disposition is strengthened by the holistic approach of traditional medicine. (Table 3).

TRADITIONAL ETIQUETTE

Participants in the FGs are deeply immersed in traditional etiquette or protocol. They emphasised the need to obtain the permission of their husbands and leaders before they could participate in the discussions. A married woman is not expected to be outgoing or mix freely with strangers as these are "forbidden bahaviours" that have dire consequences for pregnancy and childbirth.

More specifically, women are excluded from commenting on normative behaviour or standards. We also emphasise that matters concerning sex, reproductive organs, conception and complications related thereto as well as birth control or family planning are not readily discussed by the people. This has been a longstanding obstacle to sex education among a people with high fertility.

KNOWLEDGE, ATTITUDE, AND PRACTICES OF TRADITIONAL BIRTH ATTENDANTS

Generally, the traditional birth attendants share the same beliefs and practices with the wider population. They provide routine antenatal and puerperal care, assist during deliveries, and treat or manage complications that may arise from these. Apart from occasionally and reluctantly referring their patients, there were no differences in the behaviour of trained compared with untrained traditional birth attendants (some had received some basic training from the personnel of the Federal Ministry of Health and the World Health Organisation).

According to traditional birth attendants, there are different and special medicaments that a woman must take in each of the nine months of pregnancy if she is to have a problem free conception. For instance, she must take the "medicine for preventing haemorrhage" in the first and last months of pregnancy. In all, tradional birth attendants identified five possible complications that may occur during pregnancy or delivery as pains, heat in the womb, miscarriage, bleeding, and babies assuming abnormal positions in the womb.

The practices of traditional birth attendants have important implications. Treatment for both antepartum and postpartum haemorrhage entails giving by mouth a powdery substance prepared from burning the bark of an unidentified tree along with another herbs and condiments. A final practice is the induction of bleeding after delivery to eliminate "bad" blood.

The confidence of the traditional birth attendants deserves special attention. They claim that there is no obstetric complication beyond their competence. This attitude is similar to that of other traditional healers who claim to know practically everything about 
Table 3 Rural population and traditional health care delivery

\begin{tabular}{ll}
\hline Identified reason for preference of traditional medicare & $\begin{array}{l}\text { \% Of total } \\
\text { respondents }\end{array}$ \\
\hline Accessibility and availability & 100 \\
Adaptability & 68 \\
Superiority (acceptability) & 73 \\
Known delays at modern centres & 84 \\
Cheapness & 100 \\
& $\mathrm{n}=385$
\end{tabular}

every ailment. An incredulous finger is even pointed at modern health facilities where personnel, equipment, and supplies are invariably deficient. These beliefs explain their reluctance to refer patients to modern health institutions.

\section{Discussion}

In this study, factors in the community that have implications for maternal mortality and morbidity have been identified. The FGs and interviews have shown that the people in the community have a fairly good knowledge of what complications, especially haemorrhage, in pregnancy are, and how fatal these could be. Yet there are attitudes, practices, and situations that may keep women away from, or delay the decision to seek modern obstetric care particularly in emergencies.

It is unfortunate that the people still indulge in the practice of inducing bleeding after delivery "to cleanse the women of bad blood" despite knowing full well how dangerous bleeding could be. And this is an age long practice.

The traditional belief that bleeding in pregnancy could be caused by "evil or supernatural powers" and that this bleeding could only be arrested by diviners are very dangerous trends. These women surely stand a chance of bleeding to death. It is also paradoxical that these women who need all the nutrients they could muster to fight disease and possibly replenish any blood they might lose are barred from eating "sweet foods" like milk. We appreciate that barring pregnant women from "sweet foods" may be a cultural mechanism for preserving delicacies especially for menfolk. But we are confronted with beliefs that lead to real dangers. The "health belief model" may adequately explain our scenarios but the absence of rationality in the patients' belief is well evident.

What is even worse is the fact that the traditional birth attendants, who are supposed to manage these complications, share the same beliefs and practices with the general population. Yet for reasons of accessibility, availability, and acceptability, among others, women in rural areas are tied to traditional birth attendants. Thus community based factors, and not just inadequate health services, keep maternal mortality and morbidity high in this area.

We are particularly concerned about the mutual hostility existing between modern and traditional health care delivery systems. While modern practitioners denigrate and deprecate traditional healers, the latter proclaim their art to be superior. The cold war has tended to entrench the cult mentality of traditional heal-

\section{KEY POINTS}

- Upgrading modern healthcare facilities to provide effective obstetric care, encourages pregnant women to use them irrespective of perceived causes of complication.

- Because non-hospital and non-medical factors are implicated, a well planned maternal health programme should not exclusively focus on facilities and competent personnel.

- Because of long held beliefs and practices, reduction of maternal morbidity and mortality will entail extensive community education.

- As traditional birth attendants are needed in maternal healthcare for reasons of acceptability, adaptability, and accessibility, their skills should be upgraded.

- Because traditional health practice is important, collaboration with modern practice is imperative.

ers who normally do not reveal their formulas. Yet the need for collaboration between the modern and the traditional in health care delivery is widely acknowledged.

The nature of the problems identified and highlighted show that interventions aimed at reducing maternal mortality and morbidity will entail extensive community education. This will definitely not be easy as age long held beliefs and practices die hard. An innovation will be to win over the traditional hierarchy before reaching out to the people.

Besides community education, it is important that the quality of care in the hospitals is improved. This, in fact, ought to be a first step in the campaign against maternal mortality. Such effort would be in the form of strengthening their capacity to deal with obstetric emergencies, through improving the supply of drugs and the consumables, the establishment of blood donor schemes and blood banks. Another strategy would be the mounting of refresher and reorientation workshops for the health staff and, quite importantly, the traditional birth attendants (Maine $\mathrm{D}$, et al. International Safe Motherhood Conference, 1987). If pregnant women receive good quality care from these centres, they obviously would be encouraged to patronise them, no matter their perceived causes of the complications.

In trying to understand the factors associated with maternal mortality and morbidity, it is important to consider non-hospital and nonmedical factors as has been done in this study. A well planned maternal health programme, which focuses exclusively on the provision of state of the art equipment and the most qualified and dedicated personnel in most of the Third World, may turn out to be just inadequate. A thorough understanding of existing knowledge, beliefs, attitudes, and practices may be just as important. Old habits die hard and 
agents of change and modernisation should therefore be wary of grafting new ideas onto a largely unreceptive social structure.

Finally, although the goal of our operations research project is to contribute towards the development of an effective programme for obstetric care, there is no doubt that such a goal is achievable only within the framework of overall national development. Healthcare delivery cannot improve in isolation. Other social, cultural, spatial, and environmental variables must be considered.

The authors are grateful to the Prevention of Maternal Mortality Network Team at the Centre for Population and Family Health, Columbia University School of Public Health, New York for technical assistance.
Funding: this study is based on a multi-disciplinary operations research by the Prevention of Mortality Network (PMN) Benin City Team. Funding was provided by the Carnegie Corporation of New York and technical assistance by the PMM Team of the Center for Population and Family Health, School of Public Health, Columbia University, New York.

Conflicts of interest: none.

1 Rosenfield A, Maine D. Maternal mortality: a neglected tragedy. Where is the ' $M$ ' in 'MCH'? Lancet 1985; ii:83-5. 2 Grant JP. State of the world's children. New York: Oxford University Press, 1990.

3 Hickey MU, Kasonde JM. Maternal mortality at the University Teaching Hospital, Lusaka. Medical fournal of Zambia 1977;11:74-8.

4 Bertrand TJ, Brown JE, Ward VM. Techniques for analysing focus group data. Evaluation Review 1992;16:198-209.

5 Timyan J. Community Primary Health Care Project in Boake, Cote D'Ivoire. Abidjan: Columbia University Centre for Population and Family Health, 1987.

6 Anyiam C, Availability, accessibility, acceptability, and adoptability. Four attributes of Ethno-Medicine. Soc Sci Med 1982;45:803-11. 